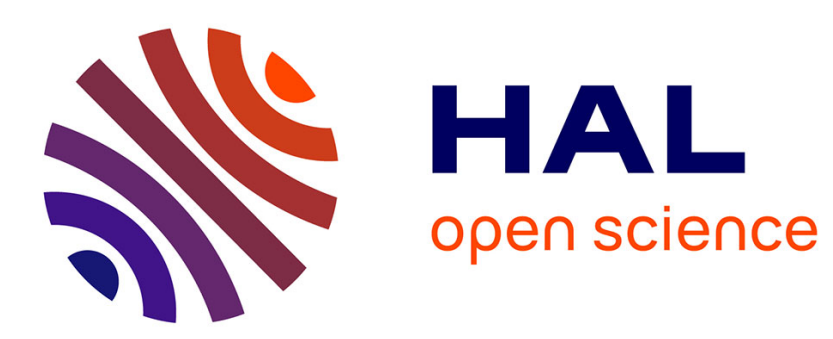

\title{
Introduction: Associated Motion as a grammatical category in linguistic typology
}

\author{
Antoine Guillaume, Harold Koch
}

\section{To cite this version:}

Antoine Guillaume, Harold Koch. Introduction: Associated Motion as a grammatical category in linguistic typology. Guillaume, Antoine \& Harold Koch. Associated motion, De Gruyter Mouton, 2021, Associated motion, 978-3-11-069200-6. 10.1515/9783110692099-001 . halshs-02917416v2

\section{HAL Id: halshs-02917416}

\section{https://shs.hal.science/halshs-02917416v2}

Submitted on 26 Feb 2021 (v2), last revised 18 Aug 2022 (v3)

HAL is a multi-disciplinary open access archive for the deposit and dissemination of scientific research documents, whether they are published or not. The documents may come from teaching and research institutions in France or abroad, or from public or private research centers.
L'archive ouverte pluridisciplinaire HAL, est destinée au dépôt et à la diffusion de documents scientifiques de niveau recherche, publiés ou non, émanant des établissements d'enseignement et de recherche français ou étrangers, des laboratoires publics ou privés. 


\title{
Antoine Guillaume and Harold Koch \\ 1 Introduction: associated motion as a grammatical category in linguistic typology
}

\begin{abstract}
This volume is the first book-length presentation of the relatively newly established grammatical category of Associated Motion. It provides a framework for understanding a grammatical phenomenon which, though present in many languages, has gone unrecognised until recently. Previously known mainly from languages of Australia and South America, grammatical AM marking has now been identified in languages from most parts of the world (except Europe) and is becoming an important topic of linguistic typology. The 22 chapters provide a thorough introduction to the subject, discussion of the relation between AM and related grammatical concepts, detailed descriptions of AM in a wide range of the world's languages, and surveys of AM in particular language families and areas. All of the studies are richly illustrated by means of (approximately 2000) example sentences.
\end{abstract}

Keywords: associated motion, direction, aspect, location, typology, complexity, implicational hierarchies

\section{Introduction ${ }^{1}$}

Associated Motion (AM) is a relatively newly established descriptive and comparative concept that we define as a verbal grammatical category, separate from tense, aspect, mood and direction, whose function is to associate, in different ways, different kinds of translational motion (spatial displacement / change of location) to a (generally non-motion) verb event. As an illustration, example (1), from the Amazonian language Cavineña, shows seven suffixes (out of an inventory of 12) expressing different AM values, in combination with the verb 'see'.

1 This introductory section is an updated summary of Guillaume (2016: 81-94, 2017a).

Antoine Guillaume, Laboratoire Dynamique du Langage (CNRS \& Université Lumière Lyon 2), antoine.guillaume@cnrs.fr

Harold Koch, Australian National University, harold.koch@anu.edu.au

https://doi.org/10.1515/9783110692099-001 
(1) Cavineña (Takanan; Guillaume 2006; 2008; 2009)

$\begin{array}{ll}\text { ba- } & \text { 'see O' } \\ \text { ba-ti- } & \text { 'go and see O' } \\ \text { ba-na- } & \text { 'come and see O' } \\ \text { ba-aje- } & \text { 'see O while going' } \\ \text { ba-be- } & \text { 'see O while coming' } \\ \text { ba-kena- } & \text { 'see O } \underline{\text { and go' }} \\ \text { ba-dadi- } & \text { 'see O while O is moving away' } \\ \text { ba-tsa- } & \text { 'see O while O is approaching' } \\ \text { etc. } & \end{array}$

AM can be expressed by verbal affixes, as in (1), but also by clitics, particles or auxiliaries, which, in different linguistic traditions, receive a wide range of descriptive labels such as "motion / motion-with-purpose / purposive / intentional", "(deictic) directional / directive", "ven(i)tive / andative / itive", "hither / thither", "centrifugal / centripetal”, "cis- / trans- / dis- / (re-)locative", "displacement" or "(secondary / locative) aspect".

The category of AM is noteworthy from a theoretical point of view because it shows, among other things, that in some languages the "fact-of-motion" (Talmy 1985,2007 ) can be encoded grammatically, by way of affixes or other grammaticalised elements, and not necessarily (or not only) lexically, contrary to what is generally assumed (Guillaume 2006: 433-435; Levinson \& Wilkins 2006: 534). As pointed out by several authors, motion expression in AM falls outside of Talmy's motion event typology (verb frame / satellite frame distinction) because this typology only takes into consideration situations where the motion component is expressed by a lexical verb root (Slobin 2004: 243; Wilkins 2004: 147; Guillaume 2006: 433-435; Schultze-Berndt 2007: 223-224).

The phenomenon of AM was first recognised and labelled in the 1980s by linguists describing the verbal morphology of Aboriginal languages of Central Australia (starting with Koch 1984; Tunbridge 1988; Wilkins 1989, 1991). In the 2000s, the term "associated motion" was borrowed from Australianist linguistics in studies of similar morphemes in languages from the Americas in Western Amazonia (starting with Guillaume 2000, 2006, 2008, 2009; Sakel 2004), Central America (starting with Zavala Maldonado 2000; O'Connor 2004) and North America (Dryer 2002, 2007). In this period, one can also mention the first identification of AM in a language of Papua New Guinea by Levinson (2006: 197-199). Finally, a decade later, AM was also identified in languages from most of the rest of the world with the notable exception of Europe - in Africa (starting with Voisin 2010, 2013; Kawachi 2011; Renaudier 2012: 97; Belkadi 2014, 2015, 2016; Kießling \& Bruckhaus 2017; Persohn 2018), Asia (starting with Jacques 2013; Konnerth 2014: 232, 2015; 
Vittrant 2015: 588-589; Stoynova 2016; Boro 2017; Alonso de la Fuente \& Jacques 2018) ${ }^{2}$ and a few more cases in Papua New Guinea (Dryer 2013; Cleary-Kemp 2015).

The exploration of AM in languages from different parts of the world and different families has revealed the multifaceted nature of the phenomenon, in terms of the wide range of ways it is manifested cross-linguistically, from dedicated to non-dedicated systems, highly elaborated to very simple inventories, varied morphological exponence (affixes, clitics, particles, etc.) with different statuses (derivational, inflectional, neither), and possible etymologies and development paths.

In the remainder of this chapter, we first review several landmark contributions in the development of the field of AM studies (\$2), before zooming in on a number of important issues that run throughout the papers of the volume: parameters of AM (§3), AM and other grammatical categories (§4) and further issues (§5). Finally, in $\S 6$, we summarise the contents of the specific chapters.

\section{Landmark contributions in the development of the field of AM studies}

In this section, we review three important findings which have paved the way for the study of AM in general and more specifically in the studies in this volume: the original recognition of the AM phenomenon in dedicated AM systems (§2.1), the subsequent identification of AM in non-dedicated systems (§2.2), and the first typological studies and proposals for implicational hierarchies (§2.3).

\subsection{Dedicated AM}

A first major development in the field of AM studies was the recognition and exploration of the phenomenon in a number of extensive studies of the Arandic languages of Central Australia (Koch 1984; Wilkins 1989, 1991) and Takanan languages of Western Amazonia (Guillaume 2006, 2008, 2009, 2013; Vuillermet 2012, 2013). These studies, which provided the main impetus for the recognition of AM as a phenomenon of cross-linguistic relevance, dealt with highly elaborated and articulated

2 For more recent studies on AM in Asian languages, see Lamarre (2020), Lamarre et al. (Under review) and Genetti et al. (under review). Of particular note is the recognition, in the first two papers, of AM in Standard Mandarin and Japanese, two languages which have been extensively studied in the past. 
systems, expressed by inventories of sometimes up to 15 grammaticalised markers in paradigmatic opposition (as in Mparntwe Arrernte), all dedicated to the expression of contrasting AM values. Crucially, the observation that these values were quite similar across the languages of the two languages families suggested a number of preliminary generalisations about the semantic parameters according to which AM systems are structured and can be compared cross-linguistically. It was found that, at the higher level of organisation, the recurrent semantic contrasts that distinguish AM forms are the argument role of the moving figure (subject versus non-subject, generally the object), the temporal relation between the motion and the verb event (prior versus concurrent versus subsequent), the path of motion (toward versus away from deictic centre, upward versus downward, straight versus return, etc.), and the aspectual realisation of the verb event (perfective / punctual versus imperfective / continuous / repeatedly); see (1) above for an illustration of several of these contrasts in the Takanan language Cavineña. Subsequently, these parameters proved useful in identifying and describing other AM systems in languages from all over the world. These included systems somewhat similar to the Arandic and Takanan ones, in terms of semantic structure and degree of elaboration. This was the case, for instance, in a number of other Western Amazonian languages such as the isolate language Mosetén (Sakel 2004: 272-288), the Arawak language Trinitario (Rose 2015), and several languages of the Panoan family (Guillaume 2017b). But the newly recognised AM systems also included much simpler ones, with inventories sometimes limited to just one or two markers, as in, for instance, several African languages of the Atlantic branch of the Niger-Congo family (Voisin 2010, 2013), Japhug from the Rgyalongic branch of Sino-Tibetan (Jacques 2013); see also many such simple systems reported by Guillaume (2016) for South American languages. The simple system of AM in Wolof (Atlantic), which is restricted to a pair of subject prior motion markers in a single contrast (itive versus ventive path), is illustrated in (2). ${ }^{3}$

(2) Wolof (Atlantic, Senegal)

a. Dafa dox-i ci tefes gi.

EV.3SG walk-Go\&Do LOC beach DEF

'He went to walk on the beach.' (Voisin 2013: 142)

b. Waa-dëkk bépp a wall-si woon.

village_inhabitant all ES rescue-COME\&DO PST

'The whole village came to rescue.' (Voisin 2013: 142)

3 In the Wolof examples in (2), EV stands for 'emphatic verb' and ES for 'emphatic subject'. 


\subsection{Non-dedicated AM}

A second significant development in the field of AM studies was the recognition in a number of African languages of AM systems in languages which do not have dedicated AM markers, but markers which normally (or primarily) express other (non-AM) meanings, and only display AM meanings in specific contexts (Belkadi 2014, 2015, 2016; building on observations in Bourdin 2006). Named D-AM (for "AM marked by deictic directionals") by Belkadi (2015: 50), this phenomenon is found to be characteristic of what is generally and indistinguishably called "deictic directionals" in the description of languages from the Afro-Asiatic (Berber, Chadic, Cushitic) and Nilo-Saharan (Nilotic) families. "Deictic directionals" in these languages consist of markers which primarily operate on motion verbs and (unless they have developed non-spatial meanings) specify the path (deictic orientation) of a motion already encoded by the verb. In (3a), for instance, the ventive enclitic $=d$ of the Berber language Taqbaylit (Kabyle) specifies the path of a 'jumping' motion encoded by the verb root. In this context, the deictic directional does not express AM; it does not contribute a motion component distinct from that of the (motion) verb event. Yet there are contexts when the deictic directionals can give rise to AM readings similar to those expressed by dedicated AM markers, as when used with (at least certain) non-motion verbs. In (3b), for instance, the same ventive enclitic $=d$ in Taqbaylit contributes a separate component of subsequent motion (specified for a ventive path) to the (non-motion) 'reading' event encoded by the verb root.

(3) Taqbaylit (Berber, Algeria)

a. non-AM meaning (path only)

t-jjlb $\quad=\boldsymbol{d}$ yr tabla.

3SG.F-jump.PRF = VEN to table

'She jumped on the table (in the direction of the speaker).' (Belkadi 2015: 64)

b. AM meaning (subsequent motion and path)

t-yra $\quad$ d $\quad$ taktaf

3SG.F-read.PRF =VEN book

'She read the book somewhere else and came back (to the location of the speaker).' (Belkadi 2015: 64)

Interestingly, it was observed that when used with AM meanings, many of these non- (or less) dedicated AM systems do not behave as otherwise expected. Typically, as pointed out by Belkadi (2015), unlike what happens in dedicated 
AM systems, their exact AM values are not fixed but are dependent on context (inherent semantics of the verb, TAM settings, pragmatic situation, etc.). In the Cushitic language Somali, for instance, depending on the communicative situation, the subsequent motion that can be expressed by the 'itive' clitic sii, can relate either to the subject argument of the verb (4i) or to a non-subject participant (4ii).

(4) Somali (Cushitic, Bourdin 2006: 18)

wuxu sii joog-aa London

FOC:3SG.M ITIVE stop/stand-PRS:3sG.M London

(i) 'He is in London right now and will continue on his way (towards a place where I am not).'

(ii) 'He is in London, where I or somebody else is going to join him.'

And in the same language, the ventive clitic soo can express all of the three main possible temporal relation values: prior motion (5i), concurrent motion (5ii), subsequent motion (5iii), as well as the more complex prior plus subsequent return motion (5iv).

(5) Somali (Cushitic, Bourdin 2006: 17-18)

soo seexo

VEN sleep:IMP.2sG

(i) 'Come sleep over here!' [face-to-face communication]

(ii) 'Get somerest (while you're traveling towards here)!' [phone conversation]

(iii) 'Get some rest (and then we'll get together)!' [phone conversation]

(iv) 'Go have a rest (and then come back here).' [face-to-face communication]

In dedicated AM systems, each of these different values (subject versus nonsubject motion, prior versus concurrent versus subsequent motion), if expressible, is normally encoded by way of a distinct marker.

\subsection{Typology of AM}

Finally, a third important development in the field of AM studies was a number of tentative typological proposals, in terms of implicational hierarchies, that make predictions in the way AM systems are structured cross-linguistically.

A first proposal, by Guillaume (2016), correlates the degree of complexity in the formation of AM systems (number of contrasting values) with the types of semantic values being manifested. On the basis of a survey in 44 South American 
languages from 36 distinct families or isolates, this typology included two implicational hierarchies.

The first hierarchy, based on the parameter of temporal relation and a suggestion by Levinson \& Wilkins (2006: 534), predicts that, if a language has a marker for subsequent motion, it will also have a marker for prior and/or concurrent motion, and if it has a marker for concurrent motion, it will also have a marker for prior motion (prior motion > concurrent motion > subsequent motion).

The second hierarchy, based on the parameter of moving argument, states that if a language has an object AM marker, it normally has a subject AM marker as well, with a restriction that the subject AM inventory must be complex (in terms of number of AM morphemes) (motion of the subject (complex inventory) $>$ motion of the object).

A second typological proposal, by Belkadi (2016), makes generalisations as to which readings, directional versus $A M$, particular semantic classes of verbs normally yield in non-dedicated polysemous (D-AM) systems. On the basis of a survey in 20 languages from the four main linguistic phyla in the African continent, Belkadi finds that on the following scale, the more the verbs are on the left-hand side, the more they tend to have directional readings, and the more they are on the right-hand side, the more they tend to have AM readings: Path motion $>$ Motion translational $>$ Causative motion $>$ Perception $>$ (Natural phenomena and bodily secretions?) > Activities not involving translational motion $>$ States.

\section{Parameters of AM}

The typology of AM has been centred on three major semantic parameters: the temporal relation between the motion and the main event, the direction of the motion, and the grammatical role of the moving figure. Some further refinements are offered in the chapters of this book.

\subsection{Direction}

It should be noted at the outset that some authors refer to this dimension as "path" or "orientation" rather than "direction". Directions found in AM systems are frequently the deictic ventive (toward speaker) and itive (away from speaker) values. Note that in some languages, the deictic centre might be the addressee rather than the speaker (Otero ch. 20). But other directions also occur, including 'return' (Koch ch. 7), and, in the vertical dimension, 'up', 'down', and 'level' 
(Schokkin ch. 10, Jacques et al. ch. 21). Included among AM markers are ones that indicate only the "fact-of-motion", with no specific direction (e.g. 'do while going along') and others that express indirect motion, such as random direction ('do here and there'). The latter, which may be called "distributive", is sometimes treated as AM but sometimes not, especially when its primary function appears to be to signal the spatial distribution of the event ('do in different places') rather than actual motion (see Koch ch. 7, Tallman ch. 11).

Efforts to establish a typology of AM are somewhat hampered by an overabundance of terminology, resulting partly from different descriptive traditions. As a guide to readers we provide in Table 1 a list of equivalents that are used by authors of these chapters (many further terms are used in the language descriptions on which these studies are based). Note that certain terms are used for different senses by different authors. The label based on the English gloss 'go' is ambiguous between a deictic sense 'away from speaker' and a neutral (unspecified) direction. "Andative" is used either for a deictic (away from speaker) sense or for motion in no particular direction ('go along'); some authors use "ambulative" for this second sense, while others use "ambulative" in a more distributive sense or for a specific "around' meaning. "Returnative" has been used not for movement back to a prior location but for bidirectional movement (as noted by Dryer ch. 4). Our preferred terms are given first in each set.

Table 1: Equivalent directional terms.

\begin{tabular}{ll}
\hline Direction & Terms \\
\hline toward deictic centre & $\begin{array}{l}\text { ventive, venitive, centripetal, cislocative, HITHER, TOWARD, } \\
\text { COM(ING) }\end{array}$ \\
\hline away from deictic centre & $\begin{array}{l}\text { itive, andative, centrifugal, translocative, THITHER, HENCE, AWAY, } \\
\text { GO(ING) }\end{array}$ \\
\hline no specific direction & andative, ambulative, mobilative, MOT(IVE) ALONG, NEUTRAL, \\
& GO(ING) \\
\hline indirect, multiple locations & ambulative, distributive, aRound, HERE AND THERE, HITHER AND \\
& THITHER, RANDom, AIMLESS, circumlocative, circular \\
\hline returning & reversive, returnative, BACK \\
\hline bidirectional & roundtrip, counterdirectional, returnative, GO\&DO\&RETURN \\
\hline reach endpoint & adlocative, arrive \\
\hline depart & LEAVE \\
\hline
\end{tabular}




\subsection{Temporal relation}

Beside the temporal relation distinctions of prior (P), concurrent (C) and subsequent (S) motion, it is necessary to recognise polysemous markers that can flexibly indicate two or more relations $(\mathrm{P} / \mathrm{C}, \mathrm{C} / \mathrm{S}, \mathrm{P} / \mathrm{C} / \mathrm{S})$ : for examples see Dryer ch. 4, Belkadi ch. 5, Vidal \& Payne ch. 12, Voisin ch.16, Creissels \& Bassène ch. 17. A further complication is the encoding of two sequential motions $(\mathrm{P}+\mathrm{S})$, typically in opposite directions (i.e. a round trip 'go and do and return') - see Ross ch. 2, Dryer ch. 4, Koch ch. 7, Tallman ch. 11, Dryer ch. 13, Jacques et al. ch. 21, Pakendorf \& Stoynova ch. 22. Perhaps related is interrupted motion in a consistent direction ('go and do then go again' or 'do while passing by') - see Ross ch. 2, Dryer ch. 4 - which however can be treated in some languages as an aspect-like punctual action within concurrent motion (= 'do once on the way') - see Koch ch. 7. Some scholars (e.g. Ross ch. 2), have indicated exceptions to Guillaume's (2016) temporal relation hierarchy P > C > S (cf. §2.3). Given that most of these exceptions (Reed \& Lindsey ch. 9, Payne ch. 18, Kawachi ch. 19, Otero ch. 20) are in systems of the D-AM type, it is worth reconsidering to what extent the hierarchy is dependent on the type of AM system involved.

\subsection{Argument role of the moving figure}

A complication to the distinction of subject versus non-subject (usually object) as the moving figure is the situation where the subject and object together move after some action (e.g. 'do and bring') - see Jacques et al. ch. 21 and, earlier, Belkadi (2015: 61, 65). Contributors have pointed out some exceptions to Guillaume's (2016) generalisation that movement of a non-subject presupposes movement of the subject (cf. §2.3) - see Vidal \& Payne ch. 12 for the D-AM system of Pilagá. Movement of the object of caused motion verbs (e.g. 'take and come/ go') is characteristic of directional systems (Schokkin ch. 10, Otero ch. 20), so it is not surprising if this occurs in D-AM systems as well. Another exception to the generalisation concerns perception verbs in certain languages, also typically with D-AM systems, where expressions like 'see (object) coming/going' are frequently encountered (Ross ch. 2, Belkadi ch. 5, Creissels \& Bassène ch. 17). 


\section{AM and other grammatical categories}

AM has been characterised as a grammatical category separate from other typical verb categories such as tense, aspect, mood, and direction. Yet it bears some relations to many of these, and sometimes as well as to categories such as location, speed, and the roles and even persons of arguments.

\subsection{AM versus motion with purpose}

Prior AM can be hard to distinguish (in descriptions) from motion-with-purpose constructions (Lovestrand \& Ross ch. 3), which express meanings such as 'go/ come in order to do', with no implication that the doing is actually accomplished. These two constructions may overlap in irrealis (future, imperative) contexts (Jacques et al. ch. 21, Pakendorf \& Stoynova ch. 22), and Prior AM may develop historically from motion-with-purpose constructions (Koch ch. 7).

\section{2 $\mathrm{AM}$ and direction}

The motion co-event signaled by AM markers typically includes a direction specification (see §3.1). Directional markers are another kind of grammatical specification that in many languages mark the direction of verbs with inherent motion semantics. In some languages, directional markers which typically occur with motion verbs may be used in some circumstances to add a motion event to non-motion verbs, and therefore express AM. These have been called, following Belkadi (2015), D-AM systems (for "AM marked by deictic directionals”) (§4.2); see Reed \& Lindsey’s (ch. 9) alternate proposal to rename D-AM as "inferential AM". About half of the specific languages described here (all the African chapters except Guérois et al. ch. 15 on Bantu and to some extent Voisin ch. 16 on Atlantic, Reed \& Lindsey ch. 9, Schokkin ch.10, Vidal \& Payne ch. 12) have such D-AM systems rather than what might be called "dedicated AM", "pure AM" or "canonical AM" systems. In other languages, the reverse type of extension can be found: the AM markers can be applied to motion verbs, in which case they add only a directional component, a phenomenon called "AM-D" by Voisin ch. 16 (for primary AM system with deictic directional extensions). A number of these studies (Ross ch. 2, Lovestrand \& Ross ch. 3, Dryer ch. 4, Belkadi ch. 5, Otero ch. 20) explore overlaps between directionals and AM markers. For Koman languages, Otero ch. 20 further evaluates 
the predictions of Belkadi's (2016) hierarchy of semantic classes of verbs (cf. $\S 2.3$ ) and finds that her generalisations are generally confirmed but with some notable exceptions.

\subsection{AM and aspect}

Although AM has been characterised as a category separate from aspect, there are overlaps. Extension of AM markers to aspectual usages is especially prominent in the African systems described here. Phasal aspect may be marked by AM morphemes: inceptive has affinities with prior motion and "exchoative" (cessative) with subsequent motion (see Tallman ch. 11 for Chácobo and Otero ch. 20 for Koman languages). Tallman ch. 11 and Kawachi ch. 19 propose that AM is always aspectual. A further interaction is the fact that aspect-like contrasts are made within certain AM subcategories (cf. §2.1 on aspectual realisation of the verb event), especially concurrent motion (e.g. 'do once/repeatedly/ continuously while going'; see Vuillermet ch. 6, Koch ch. 7). Possibly related to aspectual realisation are contrasts of speed that are found within AM systems (see Koch ch. 7, §9.)

\subsection{AM and location}

AM meanings are sometimes extended to indicate the location of the action, without reference to actual movement. Creissels \& Bassène ch. 17 posit a semantic shift of the ventive marker of Jóola Fóoñi from 'do before coming' to 'do something while being away from here' - a usage for which the terms "altrilocal”, "exlocative” or "distal” have been used (Ross ch. 2, Hernández-Green \& Palancar ch. 14, Guérois et al. ch.15, Voisin ch. 16). The corresponding location near the deictic centre has been called "proximal” (Ross ch. 2).

\subsection{AM and argument structure}

While AM marking on verbs typically does not affect argument structure, in some languages adding a marker of motion permits the addition of spatial arguments (source, goal, trajectory) that are relevant to the motional component of the resulting verb (Pakendorf \& Stoynova ch. 22). Furthermore, in some African languages, apparent extensions of AM markers include the manipulation of 
semantic roles, with and without valence change (Payne ch. 18). With respect to transitivity, in some languages AM markers display a kind of "transitivity harmony"; i.e. their form is conditioned by the transitivity of the verb stem (Koch ch. 7, Tallman ch.11).

\section{Further issues}

\subsection{System complexity}

Guillaume (2016) distinguishes AM systems by degree of complexity measured by the number of contrasting values in the system (cf. §2.1). ${ }^{4}$ Ross (ch. 2, §4.4) raises the question of how complexity should be measured, whether by the absolute number of contrasts, the number of parameters in the system, the interaction of AM with other grammatical values, or even by the formal complexity of its expression (Hernández-Green \& Palancar ch. 14). Koch (ch. 7, §9.2) questions whether a language with three AM markers within a system with two values in the relative timing parameter should count as more complex than a language with four markers within a single relative timing parameter.

\subsection{Formal expression of AM}

Most studies have focused on morphological marking by verb affixes, but AM values may be expressed by serial verb constructions (Lovestrand \& Ross ch. 3), particles (Schokkin ch. 10, Dryer ch. 13), clitics (Dryer ch. 4, Belkadi ch. 5, Tallman ch. 11), or auxiliary constructions (Koch ch. 7, Guérois et al.ch.15). AM (and Directional) markers can be described in terms of their relative ordering within the verbal word or phrase (Ross ch. 2, Lovestrand \& Ross ch. 3) - e.g. whether prefixes versus suffixes, or first versus final word in a serial verb construction. Another difference is whether AM markers are formally invariant or have variants (e.g. conditioned by the transitivity of the verb stem, see Koch ch.7, Tallman ch. 11) or whether they are expressed cumulatively with other grammatical features such as Tense or Subject-Marking: the languages described by Reed \& Lindsey ch. 9 and Hernández-Green \& Palancar ch. 14 show great complexity in this sense.

4 Alternatively, this may be expressed in terms of the number of morphemes in the AM inventory. 


\subsection{Discourse function}

The AM-marked verb may introduce both the main and the motion co-events (e.g. 'go and do'). Alternatively, it may redundantly "echo” (Guillaume 2016: 91, fn. 11) a motion event already introduced by a separate motion verb (e.g. 'go ... do (after going)'. In some languages it may anticipate a motion event to be separately introduced (e.g. 'do (before going) ... go'). These alternative uses have been described as "redundant” by Koch ch. 7, "pleonastic" by Pakendorf \& Stoynova ch. 22, and "co-indexation" of motion by Tallman ch. 11. (There is no specific label for the anticipatory use, for which the term "echo" is not very suitable.) Many papers in the volume illustrate these discourse usages, and Pakendorf \& Stoynova ch. 22 provide a detailed investigation of this topic. A related topic of interest is the overall frequency of use of AM markers in discourse, as well as the relative frequency of use of particular AM markers (Vuillermet ch. 6, Tallman ch. 11, Pakendorf \& Stoynova ch. 22).

\subsection{Diachrony of AM markers}

Some genetically related languages display obviously cognate AM markers, but these are usually not sufficient to allow the reconstruction of complete AM systems (see Koch ch. 7 for Arandic and Pama-Nyungan, Hernández-Green \& Palancar ch. 14 for Otomi, Guérois et al. ch. 15 for Bantu, Payne ch. 18 for Nilotic, Jacques et al. ch. 21 for Gyalrongic, and Pakendorf \& Stoynova ch. 22 for Tungusic languages). These papers also offer many suggestions about the origins of the forms that mark AM. While verbal origins have been known for a long time (Koch 1984; Austin 1989; Wilkins 1991; Guillaume 2013), further evidence is provided here for verbal sources of several kinds. Verbs 'come' and 'go' are especially likely etymological sources (Jacques et al. ch. 21). Former auxiliary phrases are indicated for many Pama-Nyungan languages (Koch ch. 7) as well as for Bantu languages (Guérois et al. ch. 15). Serial verb constructions are argued as the source for Paluai AM markers (Schokkin ch. 10). In some situations where verbal origins are suggested for AM markers, details of their presumed earlier construction are not recoverable (or at least not explicitly discussed). It is apparent that attested AM markers reflect different degrees of grammaticalisation from their source constructions, a fact which sometimes makes it hard to be certain about their synchronic status. A non-verbal source of AM markers, not previously appre- 
ciated, is directional affixes, particles or clitics (Osgarby ch. $8,{ }^{5}$ Vidal \& Payne ch. 12). Another diachronic development, apart from origins, is the further evolution of AM markers to non-AM values such as pure direction (Voisin ch. 16), aspect (Tallman ch. 11), and altrilocality (Creissels \& Bassène ch. 17). These diachronic developments also present problems for their synchronic analysis.

\subsection{AM and language contact}

Previous studies have argued that, in Central Australia and Western Amazonia, AM is a highly diffusible category spread through language contact (Austin 1989; Wilkins 1991; Dixon 2002: 201-202; Koch 2007; Guillaume 2016). Further support for the influence of contact on the development of AM systems is provided in a number of papers in this volume (see especially Osgarby ch. 8, Voisin ch. 16).

\subsection{Geographical distribution of AM}

AM has been found to occur in languages of all inhabited continents except Europe. This volume adds considerably to the situation in Africa and North and Central America, but also includes Papuan and Oceanic languages. Not all parts of the world have been systematically studied, however.

\section{Summary of the chapters}

The introduction so far has set out the general framework within which studies of AM have been conducted and has highlighted some issues under discussion. In this section we summarise the contents of specific chapters. The contributions are ordered geographically.

First, however, we provide an indication of the overall scope of the papers, in terms of the coverage of the world's languages. Three of the chapters have worldwide scope: Ross ch. 2 on AM and directionals, Lovestrand \& Ross ch. 3 on serial verb constructions and motion semantics, and Dryer ch. 4 on the overlap of AM and directionals. Two have continental scope: Belkadi ch. 5 on Africa and Dryer ch. 13 on North and Central America. Eight papers survey language families: Koch ch. 7 on

5 Here it is suggested that the ventive AM marker in Mudburra derived from a former directional enclitic, which in turn reflected a non-subject enclitic first person pronoun. 
Pama-Nyungan (Australia); Guérois et al. ch. 15 on Bantu, Voisin ch. 16 on Atlantic, Payne ch. 18 on Nilotic, and Otero ch. 20 on Koman - all in Africa; Jacques et al. ch. 21 on Gyalrongic and Kiranti within Sino-Tibetan, and Pakendorf \& Stoynova ch. 22 on Tungusic - both in Asia; and Hernández-Green \& Palancar ch. 14 on Otomi in Central America. Eight papers provide detailed studies of AM in particular languages: Osgarby ch. 8 on Mudburra (Pama-Nyungan, Australia); Tallman ch. 11 on Chácobo (Panoan) and Vidal \& Payne ch. 12 on Pilagá (Guaycuruan) - both in South America; Creissels \& Bassène ch. 17 on Jóola Fóoñi (Atlantic) and Kawachi ch. 19 on Kupsapiny (Nilotic) - both in Africa; Schokkin ch. 10 (Oceanic, Austronesian); and Reed \& Lindsey ch. 9 (Pahoturi River family, Papua New Guinea).

\subsection{Part 1: General issues/perspectives}

Part 1 is devoted to issues that transcend the description of particular languages. The four papers which immediately follow this introductory chapter study relations between AM and other verbal categories and/or constructions. The fifth paper is more methodological; it provides potential researchers with ideas on how data on AM may be collected.

Ross (ch. 2) presents a quantitative typological survey of the distribution of the morphological expression of AM and the distinct but overlapping grammatical category of directionals, based on a balanced sample of 325 languages. He finds AM attested in 26\% and directionals in 35\% of these languages, and both categories in 54 languages (i.e. about $16.5 \%$ of the 325 in the sample). Parameters investigated are: direction of motion (itive, ventive, etc.); temporal relationship with the lexical verb (prior, concurrent and subsequent); moving argument (subject or object); and functional overlap of AM with directionals and other grammatical categories. Guillaume's (2016) hierarchies are tested and found to be generally supported. Ross also discusses some borderline cases which pose challenges for a precise description within the current framework of AM typology.

Lovestrand \& Ross (ch. 3) explore the semantic relationship between markers of grammatical AM and motion verbs in serial verb constructions (SVCs). Their study is predicated on the fact that AM as a grammatical category, which has largely been studied as a morphological phenomenon, can also be expressed by means of multi-verb syntactic constructions. It thus complements the preceding chapter on the distribution of AM morphology. The authors find motion and/or directional semantics to be present about $80 \%$ of their sample of 124 languages having SVCs. The most common motion SVCs are "directional SVCs", which combine a pathof-motion verb with another motion verb (typically manner of motion, e.g. 'run descend'), and "prior motion SVCs" (e.g. 'come and eat') or "purposive motion 
SVCs" (e.g. 'come to eat'), which are difficult to distinguish from each other. SVCs expressing concurrent or subsequent motion and "caused accompanied motion SVCs" (e.g. 'take and come/go') are much rarer. The authors analyse the relative order of the two verbs in motion SVCs and find a clear tendency for the "restricted" motion verb to be in the first position in prior/purposive motion SVCs and in the second position in directional SVCs and subsequent motion SVCs. They propose explanations for these ordering patterns.

Dryer (ch. 4) explores the relationship between markers of AM and directional markers. He demonstrates that it is not uncommon for the same morphemes to be used for both functions; he finds this in 56 languages, from all continents in which AM occurs. When used with verbs having inherent motion semantics, these markers do not add a motion event, nor do they indicate temporal relation between motion and event, but they specify only the direction of motion. In contrast to "pure directionals", i.e. markers that do not indicate AM, Dryer proposes, these morphemes can be interpreted as a subtype of AM, akin to prior motion, concurrent motion, and so on. His on-line supplementary materials present examples from each of the languages mentioned in this chapter.

Belkadi (ch. 5) was the first to recognise the expression of AM by deictic directionals (D-AM) in many languages of Africa, showing that well-known itive and ventive markers are sometimes used to add a motion component to non-motion verbs (see §2.2). Here Belkadi addresses the problem of how AM, especially D-AM, relates to deictic directionality. Building on proposals from the literature on event semantics, the typology of event encoding and event integration, and her earlier work on an implicational hierarchy of semantic classes of verbs (cf. §2.3), she argues for an analysis in which AM and deictic directionality form a single grammatical category. A deictic directional expresses a complex event with the verb it modifies, just like an AM marker, but unlike AM it is fully integrated with (i.e. coextensive with) the motion event encoded by the host verb.

Vuillermet (ch. 6) describes a methodological tool for eliciting AM linguistic behaviour by means of visual stimuli, in the form of a picture storybook, A Hunting Story. The scenario incorporates the main parameters established in the AM literature, and it was specifically designed to elicit AM markers. The use of this tool with speakers of Ese Ejja, an Amazonian language of Bolivia and Peru (Takanan family), yielded not only examples of much of its complex AM system but also valuable data on sociolinguistics and discourse use. The author also provides some observations on strategies used to co-express motion and non-motion events in languages (which may or may not manifest grammatical AM) other than those for which this tool was designed. 


\subsection{Part 2: Australia and South Pacific}

Part 2 begins with two studies on languages of Australia, the continent where AM was first recognised, then adds a study of D-AM in a Papuan language, Ende, plus a description of the system of directionals and AM of Paluai, an Oceanic (Austronesian) language of Papua New Guinea.

Koch (ch. 7) surveys AM in the Pama-Nyungan languages of Australia. He first updates the description of semantic contrasts within the very complex AM system of Kaytetye, the Arandic language for which the AM category was first described (Koch 1984). He then compares Kaytetye with other Arandic languages, which share similarly complex AM systems and have played an important role in early studies of AM (Wilkins 1989, 1991). The remainder of the paper is devoted to an exploration of the extent to which AM appears in other languages of the large Pama-Nyungan family, spoken across a large part of the Australian continent. It is organised according to the degree of complexity of the AM systems: very complex, with eight or more AM contrasts; moderately complex, with three to six; binary, with a two-way contrast; and languages with a single AM category. AM markers are found in 41 of the approximately 100 languages for which there is adequate data to make a judgement. The findings are summarised with respect to system complexity, semantic parameters involved, geographical distribution, and diachronic sources of the AM markers.

Osgarby (ch. 8) describes AM in Mudburra, a Pama-Nyungan language in north-central Australia in intimate contact with languages of the nonPama-Nyungan Mirndi family, which includes Wambaya, where some AM forms have been previously reported (e.g. Nordlinger 2001). Mudburra has a two-way contrast of deictic direction: away from and toward the speaker. In addition to signaling (prior or concurrent) AM with non-motion verbs, these markers may be used with motion verbs to indicate either direction (e.g. 'fall toward speaker') or an added motion co-event (e.g. 'come and fall'). Unusual features, in the Australian context, are the fact that these markers do not combine with all tense-mood values and that they occur after rather than before TAM markers; both of these features reflect their origin as directional suffixes or enclitics. Osgarby shows that diachronically Mudburra has adapted its inherited directional markers (-rni 'hither' and -rra 'thither') to express the kind of information signaled in neighbouring Mirndi languages by forms derived from earlier verbs. He further shows that languages of north-central Australia, which belong to two different families (Mirndi and Pama-Nyungan) and three separate subgroups of Pama-Nyungan, form an areal group with respect to their AM systems.

Reed \& Lindsey (ch. 9) describe the AM system of a Papuan language - a (non-genetic) group for which AM has been largely unknown (but cf. Levinson's 
2006 account of Yélî Dnye). Ende, a member of the Pahoturi River language family in southern New Guinea, has a minimal AM system of the D-AM type: a ventive directional prefix can indicate concurrent, subsequent or prior motion of the subject and sometimes of other participants. The formal expression of ventive is not straightforward, but is embedded in a complex system of verbal morphological exponence. The authors also propose a new term inferential associated motion to distinguish the D-AM type from the canonical dedicated associated motion systems like that of Kaytetye.

Schokkin (ch. 10) offers the first explicit description of AM in an Oceanic (Austronesian) language, Paluai, spoken on Baluan Island, a volcanic island in Manus Province, Papua New Guinea. Paluai has a directional system that combines three deictic values (ventive, itive and neutral) with four directions based on fixed bearings (up/inland, down/seawards, level/parallel to the shore, and unspecified). These are expressed by ten motion verbs in a serial verb construction, in which the directional verb specifies the direction of the intransitive subject or transitive object of a preceding main verb expressing motion, transfer or perception. At least seven of these directional forms can also occur as particles in a preverbal slot, between Core Aspect and Secondary Aspect slots. In this position they indicate direction with motion verbs and prior motion of subject with non-motion verbs; i.e. they function as markers of D-AM. This paper contrasts preverbal (AM or directional) and post-verbal (only directional) constructions, both of which originate from serial verb constructions.

\subsection{Part 3: The Americas}

Part 3 presents four studies from the American continents (Vuillermet's chapter in Part 1 presents further data from South America).

Tallman (ch. 11) describes a complex system of at least seven dedicated AM morphemes in Chácobo, a southern Pano language of the northern Bolivian Amazon. Most of the AM morphemes display allomorphy based on the transitivity of the verb stem. Ventive and andative directions are semantic components of several AM markers, but morphemes signaling "distributive" ('do in multiple places and multiple times') and "counterdirectional” (circular) meanings are also present. Relative timing of motion versus event may be prior, concurrent, subsequent, or prior plus subsequent ('go and do and return'). On the basis of natural text data, Tallman also studies the non-motional functions of AM markers (especially aspect and orientation), and explores from texts the extent to which each of the AM markers of prior, concurrent, and subsequent motion clearly expresses AM versus aspect or orientation/direction. He argues that the data support a fuzzy boundary between AM and other categories and suggests that this fuzziness can be measured for each AM category. 
Vidal \& Payne (ch. 12) offer a study of Pilagá, a Guaycuruan language from north-eastern Argentina, thus extending our knowledge of AM systems geographically into the periphery of the South American systems of Guillaume's (2016) survey. They describe the functions of a few (including ventive and itive) of the 14 members of a set of directional verbal suffixes. There are no dedicated affixes for AM distinct from those used for non-motion direction/location, as in other languages with D-AM systems; however, at least one non-deictic directional, 'straight ahead', glossed opposite, is used to add associated motion. The most likely target of AM is the object/patient of a transitive verb; the temporal relation between the motion and the main event is not fixed. Directional suffixes also function to indicate the location of the event and they sometimes have applicative functions.

Dryer (ch. 13) surveys AM in North and Central America, finding it to be widespread, attested in 94 languages (29 families and isolates), with only five families lacking any evidence of AM. About $70 \%$ of these languages have simple systems of just one or two AM subcategories. The highest number of contrasts is seven in Panamint (Uto-Aztecan) and six in Menomini (Algic). In terms of basic typological parameters, the author notes four temporal relations (here called "types" of $\mathrm{AM}$ ): prior, concurrent, subsequent, and prior plus subsequent (with two subtypes, "round trip" and "passing by"); their relative frequency according to language is $\mathrm{P}>\mathrm{C}>\mathrm{P}+\mathrm{S}>\mathrm{S}$. The most common directions coded by AM markers are the deictic ventive and itive (here called "andative"), but a non-deictic "random" ("ambulative", 'around') direction also occurs, typically with concurrent motion, as does "neutral" direction ('go/come and do'). Dryer presents numerous examples of the same markers being used to code AM with non-motion verbs and direction-only with motion verbs, as well as a few cases where a verb is modified by a combination of a pure directional and an AM marker (e.g. 'hither move\&do'). A summary table presents the inventories of all the languages, and a set of online supplementary materials lists and describes the AM markers in each of the 94 languages.

Hernández-Green \& Palancar (ch. 14) describe AM systems in three languages of the Otomi family in central Mexico. The languages differ in the degree of complexity of the AM system, from one (in the reduced Querétaro Otomi system) to four semantic contrasts. The moving argument is usually the subject. The directional and relative timing values of AM markers in these systems are ventive (prior, concurrent, or subsequent motion to the speaker's location), attested in all the languages; andative (concurrent motion in a direction other than toward the deictic centre); ambulative (concurrent motion in a random direction, 'here and there'), attested in one language; and adlocative (prior arrival at place of the action). Most AM categories can also be used to encode pure direction with 
motion verbs. Extended usages of AM marker include an "exlocative" (i.e. altrilocative) reading of the ventive and aspectual uses (progressive, customary) of the andative and the ambulative. A typologically interesting feature of these systems is the complexity of their formal realisation. There are no dedicated AM markers, but AM values are realised cumulatively with TAM and subject person in pre-verbal "inflectional formatives" and by stem alternations (involving consonant mutations and tone changes), both of which are morphologically conditioned by the conjugation class of the verb. The Otomi AM systems are also characterised by a substantial number of paradigmatic gaps. The authors point out that the complexity of exponence of AM is a different criterion for the complexity of AM systems than morphosemantic complexity (e.g. the number of AM subcategories).

\subsection{Part 4: Africa}

African languages, where ventive and itive directional marking has long been recognised, have been brought into the compass of AM typology by the pioneering studies of Voisin $(2010,2013)$ and Belkadi $(2014,2015)$. The six studies presented in this section describe AM systems in a representative sample of individual languages and groups of languages from the Niger-Congo and Nilo-Saharan phyla. Two chapters describe individual languages and four survey AM across a genetic group. (Examples from further African languages are presented in Belkadi's ch. 5 in Part 1.) AM in African languages is generally of the D-AM type, but dedicated AM systems do occur in Bantu and some Atlantic languages. A considerable number of extended (especially aspectual and locational) functions are also described in these papers.

Guérois, Gibson \& Persohn (ch. 15) study morphological and semantic aspects of AM across the whole Bantu family, where AM has not traditionally been recognised. They identify 54 languages with clear instantiations of AM. Most of these have systems consisting of only one or two forms, marking only prior motion; but one language, Fuliiru, marks eight subcategories involving five different directions and a contrast between prior and concurrent motion. AM markers are usually verbal prefixes originating from motion verbs constructed with a non-finite verb. Some AM forms have further evolved into markers of TAM, especially future or imperative, or location, such as altrilocality.

Voisin (ch. 16) surveys AM in the languages of the Atlantic branch of the Niger-Congo family. Some 20 languages (out of a total of 50) are considered, including representatives of all subgroups except Nalu. The AM systems generally contain few contrasting markers (one to three), which are always verbal 
affixes. Voisin classifies the languages according to whether they have: an "exclusive AM" system of dedicated AM affixes (with some non-motional extensions to markers of TAM or altrilocality); a D-AM system, where deictic directional (DD) markers attest AM readings with some specific verbs; or what she calls an "AM-D" system, which is explained as an AM system expanding toward deictic directional meanings; a few languages remain unclassified. Voisin then describes the distribution of these systems geographically and according to genetic subgroups, exploring what might have been their historical development within the family. She concludes tentatively that the dedicated AM system is the more ancient one in the family and that its markers were already "verbal extensions" rather than independent lexical motion verbs in proto-Atlantic.

Creissels \& Bassène (ch. 17) provide a detailed description of the use of a single ventive marker in Jóola Fóoñi (aka Diola-Fogny), a language of the Atlantic family spoken in Senegal. Here, as in other D-AM systems, a verbal suffix (with two allomorphs) encodes deictic direction with movement verbs, but with non-movement verbs it adds a motion component. The motional semantics of this suffix is also extended to non-motional uses, expressing locational or aspectual information ('do something while being away from here') or 'development of a process in the direction of some outcome'.

Payne (ch. 18) explores the use of directional markers across the Nilotic family. Deictic directionals (ventive and itive) are found in the verbal morphology of all three branches, to express direction or orientation with motion verbs and also to add AM to non-motion verbs - in Southern Nilotic only in conjunction with ambulative (cf. Kawachi's along morpheme in chapter 19). Payne explores further functions that presumably result from extensions of AM uses, including the manipulation of semantic roles (with or without valence change) and a large variety of aspectual senses. She further presents the results of a corpus study of Maasai texts, which shows that AM is not (any longer) the dominant function of the Maasai directionals.

Kawachi (ch. 19) describes the marking of direction and motion in Kupsapiny, a South Nilotic language of Uganda. Verbal suffixes marking deictic ventive and itive directions occur with motion verbs, but also with non-motion verbs in combination with an along marker (called "ambulative” in Payne's chapter 18) to specify (usually concurrent) associated motion of the subject or even pure aspect without motion. The author emphasises that the "along-deictic-directional" marker always involves an aspectual component of continuation or iteration.

Otero (ch. 20) examines the highly polyfunctional deictic directional (DD) verbal morphology in the five living languages of the small Koman family (possibly belonging to the Nilo-Saharan phylum) spoken around the borderlands of Ethiopia and South Sudan. These suffixes mark two or three contrasting 
deictic directions - toward the speaker, toward the addressee or away from the deictic centre (according to language), or unspecified. Their function largely depends on the semantics of the host verb: direction (of intransitive subject or transitive object) with motion verbs, and subsequent motion of subject with dynamic non-motion verbs. At the more fine-grained level, Otero finds Belkadi’s (2016) scale (see §2.3) to be generally confirmed by the Koman languages, while showing that in some of these languages one of the directional markers may indicate "exchoative" aspect rather than AM with verbs of state, and that several semantic subtypes of verbs allow alternative construals which do not conform to the predictions of Belkadi's hierarchy.

\subsection{Part 5: Asia}

AM has only recently been discussed with respect to languages of Asia, and only in three families of languages: Sino-Tibetan, Tungusic and Japonic (see references in §1). In this volume, we provide two studies that further explore AM in SinoTibetan and Tungusic. Key issues addressed in these studies have been distinguishing AM from motion-with-purpose and directionals.

Jacques, Lahaussois \& Zhang (ch. 21) survey the usage of AM in the languages of the Gyalrongic and Kiranti groups within the Sino-Tibetan family. They provide criteria for determining AM functions and for distinguishing AM from both motion-with-purpose constructions and from orientation/directional markers. Four Gyalrongic languages mark two contrasting deictic directions of prior motion of the subject ('come and verb', 'go and verb'), with prefixes grammaticalised from the motion verbs 'go' and 'come' in serial verb constructions. The Kiranti languages have more complex AM systems, with one to seven distinct markers, including: prior, concurrent, and subsequent temporal relations (plus one example of prior+subsequent 'go and do and return'); "circumlocative" direction ('go around doing'); motion in the vertical dimension (up, down, level); and joint movement of subject and object (e.g. with 'bring', 'take'). AM markers originating from verbs in serial verb constructions have in some languages further grammaticalised into aspectual markers. The authors also mention a few other languages in the Sino-Tibetan family that manifest AM marking.

Pakendorf \& Stoynova (ch. 22) survey AM in five Tungusic languages belonging to the Northern and Southern branches. All the Tungusic languages, including the now-extinct Classical Manchu, have a productive suffix, here labelled the " $n d A$-suffix", which marks prior motion of the subject in a deictically non-specific direction ('go and do'), and sometimes as well motion-with-purpose 
('go to do'). Classical Manchu also had a distinct ventive suffix, and in some languages a further AM meaning 'go and do and return' is grammaticalising from a combination of -ndA with an imperfective marker. The AM suffixes occur in three constructions: in an AM-marked independent verb construction expressing both motion and main event ('go and/to VERB') and in two "pleonastic" constructions consisting of an independent motion verb plus either an AM-inflected verb ('go ... go and/to VERB') or a dependent AM-marked converb ('go ... go to VERB'). Unlike AM-marked verbs in many other languages, the Tungusic languages allow $n d A$-verbs to express spatial arguments (goal, source, trajectory) appropriate to the relevant motion, in addition to or instead of the arguments of the base verb. The authors compare discourse frequencies of AM-related variables (transitivity of base verb, construction type, argument expression) within and across the languages studied.

Acknowledgements: We are grateful to the people who worked with us to make the publication of this volume possible, including the authors of the articles, the reviewers (Aïcha Belkadi, Philippe Bourdin, Gerrit Dimmendaal, Matthew Dryer, Patti Epps, David Fleck, Carol Genetti, Rozenn Guérois, Guillaume Jacques, Kazuhiro Kawachi, Aimée Lahaussois, Joseph Lovestrand, Patrick McConvell, Lev Michael, Tatiana Nikitina, Doris Payne, Daniel Ross, Dineke Schokkin, Sylvie Voisin, Marine Vuillermet), Jean-Christophe Verstraete and the other editors of the EALT series, and editorial assistants Julie Miess and Kirstin Boergen. We thank the organisers of the 12th Conference of the Association for Linguistic Typology (ALT), held at the Australian National University, Canberra 10-15 December 2017, where earlier versions of some of the papers in this volume were presented at a workshop on "Associated Motion". ${ }^{6}$ We also thank Kate Lindsey, Brigitte Pakendorf, Bastian Persohn, Lauren Reed and Dineke Schokkin for feedback on an earlier version of this introductory chapter. Finally, we are grateful to the ASLAN project (ANR-10-LABX-0081) of Université de Lyon, for its financial support within the program "Investissements d'Avenir" (ANR-11-IDEX-0007) of the French government operated by the National Research Agency (ANR).

6 http://www.ddl.cnrs.fr/fulltext/Guillaume/Workshop_programs/Associated\%20motion_ ALT2017_Epeire.pdf 


\section{References}

Alonso de la Fuente, José Andrés \& Guillaume Jacques. 2018. Associated motion in Manchu in typological perspective. Language and Linguistics 19(4). 501-524.

Austin, Peter. 1989. Verb compounding in central australian languages. La Trobe University Working Papers in Linguistics 2. 1-31.

Belkadi, Aïcha. This volume, chapter 5 . Deictic directionality as associated motion: Motion, complex events and event integration in African languages.

Belkadi, Aïcha. 2014. Verb meaning and deictic paths in Taqbaylit Berber. In Aïcha Belkadi, Kakia Chatsiou \& Kirsty Rowan (eds.), Language Documentation and Linguistic Theory 4. London: SOAS University of London.

Belkadi, Aïcha. 2015. Associated motion with deictic directionals: A comparative overview. SOAS Working Papers in Linguistics 17. 49-76.

Belkadi, Aïcha. 2016. Associated Motion Constructions in African Languages. Africana Linguistica 22. 43-70.

Boro, Krishna. 2017. A Grammar of Hakhun Tangsa. Eugene: University of Oregon doctoral dissertation.

Bourdin, Philippe. 2006. The marking of directional deixis in Somali: How typological idiosyncratic is it? In F. K. Erhard Voeltz (ed.), Studies in African Linguistic Typology (Typological Studies in Language 64), 13-41. Amsterdam: John Benjamins Publishing Company.

Cleary-Kemp, Jessica. 2015. Serial Verb Constructions Revisited: A Case Study from Koro. Berkeley: University of California doctoral dissertation.

Creissels, Denis \& Alain-Christian Bassène. This volume, chapter 17. Ventive, associated motion and aspect in Jóola Fóoñi (Atlantic).

Dixon, Robert M. W. 2002. Australian languages. Their nature and development. Cambridge: Cambridge University Press.

Dryer, Matthew. 2002. A comparison of preverbs in Kutenai and Algonquian. In David Pentland (ed.), Proceedings of the Thirtieth Algonquian Conference, 63-94. Winnipeg: University of Manitoba.

Dryer, Matthew. 2007. Kutenai, Algonquian, and the Pacific Northwest from an areal perspective. In H. C Wolfart (ed.), Proceedings of the Thirty-Eighth Algonquian Conference, 155-206. Winnipeg: University of Manitoba.

Dryer, Matthew S. This volume, chapter 4. Associated motion and directionals: Where they overlap.

Dryer, Matthew S. This volume, chapter 13. Associated motion in North America (including Mexico and Central America).

Dryer, Matthew S. 2013. A grammatical description of Kara-Lemakot (Studies in the Languages of Island Melanesia 2). Canberra: Asia-Pacific Linguistics Open Access Monographs.

Genetti, Carol, Kristine A. Hildebrandt, Alexia Fawcett \& Nathaniel Sims. Under review. Direction and Associated Motion in Tibeto-Burman.

Guérois, Rozenn, Hannah Gibson \& Bastian Persohn. This volume, chapter 15. Associated motion in Bantu languages.

Guillaume, Antoine. 2000. Directionals versus associated motions in Cavineña. In Alan K. Melby \& Arle L. Lommel (eds.), LACUS Forum XXVI: The lexicon, 395-401. Fullerton, CA: The Linguistic Association of Canada and the United States. 
Guillaume, Antoine. 2006. La catégorie du "mouvement associée en cavineña : apport à une typologie de l'encodage du mouvement et de la trajectoire. Bulletin de la Société de Linguistique de Paris 101(1). 415-436.

Guillaume, Antoine. 2008. A grammar of Cavineña (Mouton Grammar Library 44). Berlin \& New York: Mouton de Gruyter.

Guillaume, Antoine. 2009. Les suffixes verbaux de mouvement associé en cavineña. Faits de Langues : Les Cahiers 1. 181-204.

Guillaume, Antoine. 2013. Reconstructing the category of "associated motion" in Tacanan languages (Amazonian Bolivia and Peru). In Ritsuko Kikusawa \& Lawrence A. Reid (eds.), Historical Linguistics 2011. Selected papers from the 20th International Conference on Historical Linguistics, Osaka, 25-30 July 2011, 129-151. Amsterdam \& Philadelphia: John Benjamins Publishing Company.

Guillaume, Antoine. 2016. Associated motion in South America: Typological and areal perspectives. Linguistic Typology 20(1). 81-177.

Guillaume, Antoine. 2017a. Associated motion: Australia, South America and beyond. Presented at the Workshop on "Associated Motion", held in conjunction with the 12th Conference of the Association for Linguistic Typology (ALT), 15 December, Canberra, Australia.

Guillaume, Antoine. 2017b. Sistemas complejos de movimiento asociado en las lenguas Takana y Pano: perspectivas descriptiva, tipológica e histórico-comparativa. In Antoine Guillaume \& Pilar M. Valenzuela (eds.), Estudios sincrónicos y diacrónicos sobre lenguas Pano y Takana, vol. 39(1), 211-261. Paris: Amerindia - A.E.A.

Guillaume, Antoine \& Harold Koch. This volume, chapter 1. Introduction: Associated motion as a grammatical category in linguistic typology.

Hernández-Green, Néstor \& Enrique Palancar. This volume, chapter 14. Associated motion in the Otomi family.

Jacques, Guillaume. 2013. Harmonization and disharmonization of affix ordering and basic word order. Linguistic Typology 17(2). 187-215.

Jacques, Guillaume, Aimée Lahaussois \& Shuya Zhang. This volume, chapter 21. Associated motion in Sino-Tibetan, with a focus on Gyalrongic and Kiranti.

Kawachi, Kazuhiro. This volume, chapter 19. The 'along'-deictic-directional verb suffix complex in Kupsapiny.

Kawachi, Kazuhiro. 2011. Meanings of the spatial deictic verb suffixes in Kupsapiny, the southern Nilotic language of the Sebei region of Uganda. In Hieda Osamu (ed.), Descriptive studies of Nilotic languages (Studies in Nilotic Linguistics 3), 65-107. Tokyo: Research Institute for Languages and Cultures of Asia and Africa, Tokyo University of Foreign Studies.

Kießling, Roland \& Stefan Bruckhaus. 2017. Associated locomotion in Datooga (Southern Nilotic). In Kaji Shigeki (ed.), Proceedings of the 8th World Congress of African Linguistics (WOCAL), Kyoto 2015, 243-258. Tokyo: Tokyo University of Foreign Studies.

Koch, Harold. This volume, chapter 7. Associated motion in the Pama-Nyungan languages of Australia.

Koch, Harold. 1984. The category of "associated motion" in Kaytej. Languages in Central Australia 1. 23-34.

Koch, Harold. 2007. Language contact and the grammaticalisation of motion: a case study from central Australia. Presented at the 18th International Conference of Historical Linguistics, Montreal, August 6-11. 
Konnerth, Linda. 2014. A grammar of Karbi. Eugene: University of Oregon doctoral dissertation. Konnerth, Linda. 2015. A new type of convergence at the deictic center: second person and cislocative in Karbi (Tibeto-Burman). Studies in Language 39(1). 24-45.

Lamarre, Christine. 2020. An associated motion approach to northern Mandarin motioncum-purpose patterns. In Janet Zhiqun Xing (ed.), A Typological Approach to Grammaticalization and Lexicalization, 131-163. Berlin/Boston: De Gruyter Mouton.

Lamarre, Christine, Alice Vittrant, Anetta Kopecka, Sylvie Voisin \& al. Under review. Deictic directionals revisited in the light of advances in typology. In Laure Sarda \& Benjamin Fagard (eds.), Neglected aspects of motion-event description.

Levinson, Stephen C. 2006. The language of space in Yélî Dnye. In Stephen C. Levinson \& David P. Wilkins (eds.), Grammars of space. Explorations in cognitive diversity, 157-205. Cambridge: Cambridge University Press.

Levinson, Stephen C. \& David P. Wilkins. 2006. Patterns in the data: toward a semantic typology of spatial description. In Stephen C. Levinson \& David P Wilkins (eds.), Grammars of space. Explorations in cognitive diversity, 512-552. Cambridge: Cambridge University Press.

Lovestrand, Joseph \& Daniel Ross. This volume, chapter 3. Serial verb constructions and motion semantics.

O'Connor, Loretta. 2004. Going getting tired: associated motion through space and time in Lowland Chontal. In Michel Achard \& Suzanne Kemmer (eds.), Language, culture and mind, 181-199. Stanford: CSLI Publications.

Osgarby, David. This volume, chapter 8 . Mudburra associated motion in an areal perspective.

Otero, Manuel A. This volume, chapter 20. At the intersection of associated motion, direction and exchoative aspect in the Koman languages.

Pakendorf, Brigitte \& Natalya Stoynova. This volume, chapter 22. Associated motion in Tungusic languages: A case of mixed argument structure.

Payne, Doris L. This volume, chapter 18. The extension of 'Associated Motion' to aspect and argument structure in Nilotic languages.

Persohn, Bastian. 2018. Basic motion verbs in Nyakyusa: lexical semantics and associated motion. Studies in African Linguistics 47(1 \& 2). 101-127.

Reed, Lauren W \& Kate L Lindsey. This volume, chapter 9. "Now the story's turning around”: Associated motion and directionality in Ende, a language of Papua New Guinea.

Renaudier, Marie. 2012. Dérivation et valence en sereer. Variété de Mar Lodj (Sénégal). Lyon: Université Lumière Lyon 2 doctoral dissertation.

Rose, Françoise. 2015. Associated motion in Mojeño Trinitario: some typological considerations. Folia Linguistica 49(1). 117-158.

Ross, Daniel. This volume, chapter 2. A cross-linguistic survey of associated motion and directional.

Sakel, Jeanette. 2004. A grammar of Mosetén (Mouton Grammar Library 33). Berlin \& New York: Mouton de Gruyter.

Schokkin, Dineke. This volume, chapter 10. Preverbal directionals as markers of associated motion in Paluai (Austronesian; Oceanic).

Schultze-Berndt, Eva. 2007. On manners and paths of refining Talmy's typology of motion expressions via language documentation. In Peter K. Austin, Oliver Bond \& David Nathan (eds.), Proceedings of Conference on Language Documentation and Linguistic Theory. London: SOAS. 
Slobin, Dan I. 2004. The many ways to search for a frog. In Sven Strömquist \& Ludo Verhoven (eds.), Relating events in narrative: typological and contextual perspectives, vol. 2, 219-257. Mahwah, NJ: Lawrence Erlbaum Associates.

Stoynova, Natalia. 2016. Pokazateli “dviženija s cel'ju” i sobytijnaja struktura: suffiks -nda v nanajskom jazyke [Markers of "motion-cum-purpose" and event structure: -nda suffix in Nanai]. Voprosy Jazykoznanija (4). 86-111.

Tallman, Adam J. R. This volume, chapter 11. Associated motion in Chácobo (Pano) in typological perspective.

Talmy, Leonard. 1985. Lexicalization patterns: semantic structure in lexical form. In Timothy Shopen (ed.), Language typology and syntactic description, vol. 3, 57-148. Cambridge: Cambridge University Press.

Talmy, Leonard. 2007. Lexical typologies. In Timothy Shopen (ed.), Language Typology and Syntactic Description, 66-168. 2nd edn. Cambridge: Cambridge University Press.

Tunbridge, Dorothy. 1988. Affixes of motion and direction in Adnyamathanha. In Peter Austin (ed.), Complex sentence constructions in Australian languages (Typological Studies in Language 15), 267-283. Amsterdam: John Benjamins.

Vidal, Alejandra \& Doris L Payne. This volume, chapter 12. Pilagá directionals and the typology of associated motion.

Vittrant, Alice. 2015. Expressing motion. The contribution of Southeast Asian languages with reference to East Asian languages. In Nick J. Enfield \& Bernard Comrie (eds.), Languages of Mainland Southeast Asia: the state of the art (Pacific Linguistics 649), 586-632. Berlin: De Gruyter Mouton.

Voisin, Sylvie. This volume, chapter 16. Associated motion and deictic directional in Atlantic languages.

Voisin, Sylvie. 2010. Les morphèmes -i et -si en wolof. Sciences et Techniques du Langage, Revue du Centre de Linguistique Appliquée de Dakar 10. 21-34.

Voisin, Sylvie. 2013. Expressions de trajectoire dans quelques langues atlantiques (groupe nord). Faits de Langues. Sémantiques des relations spatiales 42. 131-152.

Vuillermet, Marine. This volume, chapter 6 . A visual stimulus for eliciting associated motion.

Vuillermet, Marine. 2012. A grammar of Ese Ejja, a Takanan language of the Bolivian Amazon. Lyon: Université Lumière Lyon 2 doctoral dissertation.

Vuillermet, Marine. 2013. Dónde, cuándo, y con quién ocurren acciones: el movimento asociado en ese ejja. In Ana María Ospina Bozzi (ed.), Expresión de nociones espaciales en lenguas amazónicas, 39-59. Bogota: Instituto Caro y Cuervo \& Universidad Nacional de Colombia.

Wilkins, David P. 1989. Mparntwe Arrernte (Aranda). Studies in the structure and semantics of grammar. Canberra: Australian National University doctoral dissertation.

Wilkins, David P. 1991. The semantics, pragmatics and diachronic development of "associated motion" in Mparntwe Arrernte. Buffalo Papers in Linguistics 1. 207-257.

Wilkins, David P. 2004. The verbalization of motion events in Arrernte. In Sven Strömquist \& Ludo Verhoven (eds.), Relating events in narrative: typological and contextual perspectives, 143-157. Mahwah, NJ: Lawrence Erlbaum Associates.

Zavala Maldonado, Roberto. 2000. Olutec motion verbs: grammaticalization under Mayan contact. In Andrew K. Simpson (ed.), Annual Meeting of the Berkeley Linguistics Society, vol. 26, 139-151. 